\title{
A Study on Sex Estimation by Using Machine Learning Algorithms with Parameters Obtained from Computerized Tomography Images of the Cranium
}

Seyma Toy ( $\sim$ seymatoy@karabuk.edu.tr)

Karabuk University

Yusuf Secgin

Karabuk University

Zülal Oner

Izmir Bakircay University

Muhammed Kamil Turan

Karabuk University

Serkan Oner

Izmir Bakircay University

Deniz Senol

Duzce University

\section{Research Article}

Keywords: machine learning algorithms (ML), computerized tomography (CT), LR algorithms, cranium skeleton.

Posted Date: September 8th, 2021

DOl: https://doi.org/10.21203/rs.3.rs-840284/v1

License: (9) This work is licensed under a Creative Commons Attribution 4.0 International License.

Read Full License

Version of Record: A version of this preprint was published at Scientific Reports on March 11th, 2022. See the published version at https://doi.org/10.1038/s41598-022-07415-w. 


\section{Abstract}

The aim of this study is to test whether sex prediction can be made by using machine learning algorithms $(\mathrm{ML})$ with parameters taken from computerized tomography (CT) images of cranium and mandible skeleton which are known to be dimorphic. CT images of the cranium skeletons of 150 men and 150 women were included in the study. 25 parameters determined were tested with different ML algorithms. Accuracy (Acc), Specificity (Spe), Sensitivity (Sen), F1 score (F1), Matthews correlation coefficient (Mcc) values were included as performance criteria and Minitab 17 package program was used in descriptive statistical analyses. $p \leq 0.05$ value was considered as statistically significant. In ML algorithms, the highest prediction was found with $0.90 \mathrm{Acc}, 0.80 \mathrm{Mcc}, 0.90 \mathrm{Spe}, 0.90 \mathrm{Sen}, 0.90 \mathrm{~F} 1$ values as a result of LR algorithms. As a result of confusion matrix, it was found that 27 of 30 males and 27 of 30 females were predicted correctly. Acc ratios of other MLs were found to be between 0.81 and 0.88 . It has been concluded that the LR algorithm to be applied to the parameters obtained from CT images of the cranium skeleton will predict sex with high accuracy.

\section{Introduction}

The main purpose of forensic anthropology is to reconstruct the biological profile of deceased individuals; that is, to predict sex, age of death, lineage and height based on the remains of skeletons ${ }^{1}$. Forensic sex prediction has taken a large place in literature since the late 1960s and identification of sex from human skeleton has been described as an important factor, even a key element in both forensic medicine and bio-archaeological context ${ }^{2-4}$. Sex prediction is an indispensable part of biological profile. Anthropologist uses the biomarkers of the skeletal system that vary between sexes to determine sex ${ }^{5,6}$.

It is noteworthy that studies have been conducted in literature for the estimation of sex almost with all bones of the human skeleton and that the accuracy of gender determination has been researched frequently by comparing with different populations. It can be seen that various bones such as femur 2,3 , patella 7,8 , mandible ${ }^{9}$, calcaneus ${ }^{10}$, metatarsal bone and phalanx ${ }^{11,12}$, occipital condyle ${ }^{13}$, hand bones 14,15 and sternum ${ }^{16}$ are used in sex prediction. It has been reported in a large number of studies in literature that cranium and pelvis bones, which are considered to be the most dimorphic areas according to skeletal parts, can be used in sex prediction by using different assessment methods $4,10,16-19$.

Identification of sex includes some inherent limitations that are affected by different factors such as ethnicity, socio-economic status, diet and geographic location. The inability to generalize the results obtained from a specific population, especially in skeletal parts such as cranium, to other populations and the need for population-specific studies increase the interest in cranium and mandible in sex determination ${ }^{4,20}$. For these reasons, all techniques reported for identifying sex are specific to related studies and they may not be applicable to different samples or data sets ${ }^{3}$.

It can be seen that methods such as discriminant analysis, machine learning algorithms (ML), support vector machine and artificial neural network are commonly used in sex prediction in which these bones 
are examined $^{2,3,7}$.

ML is a modern classifier that is used extensively in the field of engineering, and it is now gradually integrated in the field of health. These algorithms are classified as supervised, unsupervised and reinforcement. Supervised learning is algorithms that match the relationship between input and output, unsupervised learning is algorithms that match the characteristics of the data about which there is no information and reinforcement leaning is the algorithms that match the input data with desired characteristics ${ }^{20}$.

Computerized tomography (CT) is an imaging method that can show all tissues, especially bone tissue with sharp borders. In case of thin section, image orientation can be changed in three dimensions and can be taken to orthogonal plane. In this way, length and angle measurements can be calculated in a way that is less affected by orientation. With all these aspects, it provides superior results compared to studies carried out with more conventional osteometric devices ${ }^{16}$.

The aim of this study is to show the success of sex prediction by using ML with parameters obtained from CT images of cranium and mandible skeleton.

\section{Results}

Of the 25 parameters determined, 20 (NVIC, NSVC, NNL, PC, NIVA, PNIC, VIC, NIC, RML, CML, GHGA, HML, COL, CMHA, HGGC, COIC, HGGMC, HGGMA) were found to be statistically significant between males and females ( $p \leq 0.05)$. In 18 of these parameters which were found to be statistically significant, the average of the parameter used was higher in males, while the average of the parameter used was higher in females in 2 parameters (GHGA, CMHA) (Table 1, 2). 
Table 1

Comparison of parametric data of males and females

\begin{tabular}{|c|c|c|c|}
\hline Parametre & Cinsiyet & $\begin{array}{l}\text { Mean } \pm \text { std } \\
(\mathrm{cm})\end{array}$ & $\mathrm{p}$ value \\
\hline \multirow[t]{2}{*}{ NNL } & Male & $2.46 \pm 0.34$ & \multirow[t]{2}{*}{$<0.01$} \\
\hline & Female & $2.30 \pm 0.31$ & \\
\hline \multirow[t]{2}{*}{ NNZA } & Male & $120.68 \pm 11.12$ & \multirow[t]{2}{*}{0.35} \\
\hline & Female & $119.55 \pm 9.92$ & \\
\hline \multirow[t]{2}{*}{ HGGA } & Male & $120.22 \pm 6.90$ & \multirow[t]{2}{*}{0.92} \\
\hline & Female & $120.30 \pm 6.78$ & \\
\hline \multirow[t]{2}{*}{ RML } & Male & $5.29 \pm 0.51$ & \multirow[t]{2}{*}{$<0.01$} \\
\hline & Female & $4.54 \pm 0.41$ & \\
\hline \multirow[t]{2}{*}{ CML } & Male & $7.34 \pm 0.57$ & \multirow[t]{2}{*}{$<0.01$} \\
\hline & Female & $7.06 \pm 0.49$ & \\
\hline \multirow[t]{2}{*}{ GHGA } & Male & $37.05 \pm 4.60$ & \multirow[t]{2}{*}{$<0.01$} \\
\hline & Female & $38.99 \pm 4.87$ & \\
\hline \multirow[t]{2}{*}{ HML } & Male & $8.24 \pm 0.56$ & \multirow[t]{2}{*}{$<0.01$} \\
\hline & Female & $7.55 \pm 0.58$ & \\
\hline \multirow[t]{2}{*}{ COLI } & Male & $106.61 \pm 6.98$ & \multirow[t]{2}{*}{0.06} \\
\hline & Female & $105.07 \pm 7.23$ & \\
\hline \multirow[t]{2}{*}{ CMHA } & Male & $110.68 \pm 10.41$ & \multirow[t]{2}{*}{$<0.01$} \\
\hline & Female & $114.82 \pm 10.04$ & \\
\hline \multirow[t]{2}{*}{ HGGC } & Male & $12.56 \pm 0.79$ & \multirow[t]{2}{*}{$<0.01$} \\
\hline & Female & $11.44 \pm 0.69$ & \\
\hline \multirow[t]{2}{*}{ COIC } & Male & $8.61 \pm 0.73$ & \multirow[t]{2}{*}{$<0.01$} \\
\hline & Female & $7.93 \pm 0.67$ & \\
\hline \multicolumn{4}{|c|}{$\begin{array}{l}\text { (NNL: Nasion - nasal end point length, NNZA: Nasal end point - nasion - zygomatic angle, HGGA: } \\
\text { Head of mandible- gonion - gnathion angle, RML: Ramus of the mandible length, CML: Corpus of } \\
\text { the mandible length, GHGA: Gnathion - head of mandible- gonion angle, HML: Head of mandible - } \\
\text { mental foramen length, COLI: Coronoid process - obliqua line - infradental angle, CMHA: Coronoid } \\
\text { process - mandibular notch - head of mandible angle, HGGC: Head of mandible - gonion - } \\
\text { gnathion curvature length, COIC: Coronoid process - obliqua line - infradental curvature length, } \\
\text { HGGMA: Head of mandible - gonion - gnathion - mandibular notch area) }\end{array}$} \\
\hline
\end{tabular}




\begin{tabular}{|c|c|c|c|}
\hline Parametre & Cinsiyet & $\begin{array}{l}\text { Mean } \pm \text { std } \\
(\mathrm{cm})\end{array}$ & $p$ value \\
\hline \multirow[t]{2}{*}{ HGGMA } & Male & $31.15 \pm 4.10$ & \multirow[t]{2}{*}{$<0.01$} \\
\hline & Female & $25.57 \pm 3.73$ & \\
\hline \multicolumn{4}{|c|}{$\begin{array}{l}\text { (NNL: Nasion - nasal end point length, NNZA: Nasal end point - nasion - zygomatic angle, HGGA: } \\
\text { Head of mandible- gonion - gnathion angle, RML: Ramus of the mandible length, CML: Corpus of } \\
\text { the mandible length, GHGA: Gnathion - head of mandible- gonion angle, HML: Head of mandible - - } \\
\text { mental foramen length, COLI: Coronoid process - obliqua line - infradental angle, CMHA: Coronoid } \\
\text { process - mandibular notch - head of mandible angle, HGGC: Head of mandible - gonion - } \\
\text { gnathion curvature length, COIC: Coronoid process - obliqua line - infradental curvature length, } \\
\text { HGGMA: Head of mandible - gonion - gnathion - mandibular notch area) }\end{array}$} \\
\hline
\end{tabular}


Table 2

Comparison of non-parametric data of males and females

\begin{tabular}{|c|c|c|c|}
\hline Parameter & Sex & Median (min-max), (cm) & $\mathrm{p}$ value \\
\hline \multirow[t]{2}{*}{ NVIA } & Male & $76.65(69.54-86.03)$ & \multirow[t]{2}{*}{0.89} \\
\hline & Female & $76.66(43.77-86.43)$ & \\
\hline \multirow[t]{2}{*}{ NVIC } & Male & $32.41(29.04-40.50)$ & \multirow[t]{2}{*}{$<0.01$} \\
\hline & Female & $30.84(27.59-33.60)$ & \\
\hline \multirow[t]{2}{*}{ NSVC } & Male & $14.49(12.20-18.14)$ & \multirow[t]{2}{*}{$<0.00$} \\
\hline & Female & $13.49(11.43-38.97)$ & \\
\hline \multirow[t]{2}{*}{ ZA } & Male & $77.86(62.76-95.62)$ & \multirow[t]{2}{*}{0.21} \\
\hline & Female & $77.22(43.65-92.02)$ & \\
\hline \multirow[t]{2}{*}{ PC } & Male & $4.67(3.15-5.53)$ & \multirow[t]{2}{*}{$<0.01$} \\
\hline & Female & $4.14(3.06-5.53)$ & \\
\hline \multirow[t]{2}{*}{ NIVA } & Male & $43.99(14.18-73.93)$ & \multirow[t]{2}{*}{0.03} \\
\hline & Female & $43.73(37.23-51.16)$ & \\
\hline \multirow[t]{2}{*}{ PNIC } & Male & $39.47(35.32-43.93)$ & \multirow[t]{2}{*}{$<0.01$} \\
\hline & Female & $37.13(29.01-41.44)$ & \\
\hline \multirow[t]{2}{*}{ VIC } & Male & $17.78(14.02-22.53)$ & \multirow[t]{2}{*}{$<0.0$} \\
\hline & Female & $17.28(13.14-29.72)$ & \\
\hline \multirow[t]{2}{*}{ NFIA } & Male & $70.88(45.18-81.06)$ & \multirow[t]{2}{*}{0.78} \\
\hline & Female & $70.60(60.79-80.64)$ & \\
\hline \multirow[t]{2}{*}{$\mathrm{NIC}$} & Male & $34.90(31.12-38.12)$ & \multirow[t]{2}{*}{$<0.01$} \\
\hline & Female & $32.59(23.45-37.39)$ & \\
\hline \multirow[t]{2}{*}{ GA } & Male & $125.31(18.59-143.71)$ & \multirow[t]{2}{*}{0.18} \\
\hline & Female & $125.58(111.16-148.95)$ & \\
\hline COL & Male & $3.11(2.13-7.36)$ & $<0.01$ \\
\hline \multicolumn{4}{|c|}{$\begin{array}{l}\text { (NVIA: Nasion - vertex - inion angle, NVIC: Nasion - vertex - inion curvature length, NSVC: Nasion - } \\
\text { superciliary arch - vertex curvature length, ZA: Zygomatic angle, PC: Piriform aperture curvature } \\
\text { length, NIVA: Nasion - inion - vertex angle, PNIC: Piriform aperture - Nasal end point - inion } \\
\text { curvature length, VIC: Vertex - inion curvature length, NFIA: Nasion - frontal tuber - inion angle, NIC: } \\
\text { Nasal end point - inion curvature length, GA: Gonial angle, COL: Coronoid process - obliqua line } \\
\text { length, HGGMC: Head of mandible - gonion - gnathion - mandibular notch curvature length) }\end{array}$} \\
\hline
\end{tabular}




\begin{tabular}{|llll|}
\hline Parameter & Sex & Median (min-max), (cm) & p value \\
\hline HGGMC & Female & $2.81(1.94-3.85)$ & $<0.01$ \\
& Male & $29.86(17.62-33.83)$ & \\
\cline { 2 - 4 } & Female & $27.37(23.08-32.79)$ & \\
\hline $\begin{array}{l}\text { (NVIA: Nasion - vertex - inion angle, NVIC: Nasion - vertex - inion curvature length, NSVC: Nasion - } \\
\text { superciliary arch - vertex curvature length, ZA: Zygomatic angle, PC: Piriform aperture curvature } \\
\text { length, NIVA: Nasion - inion - vertex angle, PNIC: Piriform aperture - Nasal end point - inion } \\
\text { curvature length, VIC: Vertex - inion curvature length, NFIA: Nasion - frontal tuber - inion angle, NIC: } \\
\begin{array}{l}\text { Nasal end point - inion curvature length, GA: Gonial angle, COL: Coronoid process - obliqua line } \\
\text { length, HGGMC: Head of mandible - gonion - gnathion - mandibular notch curvature length) }\end{array}\end{array}$ \\
\hline
\end{tabular}

$0.90 \mathrm{Acc}, 0.80 \mathrm{Mcc}, 0.90 \mathrm{Spe}, 0.90 \mathrm{Sen}$ and $0.90 \mathrm{~F} 1$ values were found as a result of the LR algorithm. As a result of the confusion matrix performed, 27 of 30 males and 27 of 30 females were predicted correctly (Fig. 1). Of the MLs, the highest Acc, Mcc ratio was found as $0.90,0.80$ with LR algorithm. Acc ratios of the other MLs were between 0.81 and 0.88 .

$0.88 \mathrm{Acc}, 0.77 \mathrm{Mcc}, 0.88 \mathrm{Spe}, 0.88 \mathrm{Sen}, 0.88 \mathrm{~F} 1$ values were found as a result of LDA algorithm and 26 of 30 males and 27 of 30 females were predicted correctly as a result of confusion matrix. 0.83 Acc, 0.67 Mcc, 0.83 Sep, 0.83 Sen, 0.83 F1 values were found as a result of QDA algorithm and 24 of 30 males and 26 of 30 females were predicted correctly as a result of confusion matrix. $0.88 \mathrm{Acc}, 0.77 \mathrm{Mcc}, 0.88 \mathrm{Spe}$, 0.88 Sen, $0.88 \mathrm{~F} 1$ values were found as a result of RF algorithm and 24 of 30 males and 27 of 30 females were predicted correctly as a result of confusion matrix. $0.85 \mathrm{Acc}, 0.70 \mathrm{Mcc}, 0.85 \mathrm{Spe}, 0.85 \mathrm{Sen}, 0.85 \mathrm{~F} 1$ values were found as a result of ETC algorithm and 24 of 30 males and 27 of 30 females were predicted correctly as a result of confusion matrix. $0.81 \mathrm{Acc}, 0.67 \mathrm{Mcc}, 0.81 \mathrm{Spe}, 0.81 \mathrm{Sen}, 0.81 \mathrm{~F} 1$ values were found as a result of DT algorithm and 24 of 30 males and 23 of 30 females were predicted correctly as a result of confusion matrix.

\section{Discussion}

The aim of this study is to test whether sex identification can be made by using ML with the parameters obtained from cranium and mandible CT images taken to orthogonal plane. In the statistical analysis performed, NVIC, NSVC, NNL, PC, NIVA, PNIC, VIC, NIC, RML, CML, HML, COL, HGGC, COIC, HGGMC, HGGMA parameters were found to be statistically significant in distinguishing between sexes $(p \leq 0.05)$. Of the MLs tested, $0.90 \mathrm{Acc}, 0.80 \mathrm{Mcc}, 0.90 \mathrm{Spe}, 0.90 \mathrm{Sen}, 0.90 \mathrm{~F} 1$ values were found as a result of LR algorithm. It was found that 27 of 30 males and 27 of 30 females were predicted correctly as a result of confusion matrix. Acc ratios of other MLs were found to be between 0.81 and 0.88 . Forensic anthropologists constantly try to improve skeletal identification methods by using various methods in various parts of the skeleton or by developing new methods to determine gender ${ }^{4}$. Pelvis and cranium are known as the most dimorphic skeletal parts and they form the basis of sex determination researches 4,10,17-19. Bertsatos et al. ${ }^{19}$ reported that they predicted sex with an Acc ratio of $0.71-0.90$ in total according to the results of the discriminant function analysis they carried out with the parameters taken 
from the cranium. Franklin et al. ${ }^{21}$ and Dayal et al. ${ }^{22}$ reached Acc ratios of $0.88-0.90$ and $0.80-0.85$, respectively according to the results of the discriminant function analysis they carried out with the parameters taken from the cranium. In this study, $0.90 \mathrm{Acc}, 0.80 \mathrm{Mcc}, 0.90 \mathrm{Spe}, 0.90 \mathrm{Sen}, 0.90 \mathrm{~F} 1$ results were found as a result of $L R$ algorithm. Since the ML results included Mcc value which can evaluate Acc, Spe, Sen values together and which shows the reliability of algorithm, it is thought that reliability and accuracy were tested with various methods and reliable results were found in the study ${ }^{12}$.

While discriminant function analysis is one of the most widely used methods in forensic and archaeological cases for the determination of sex in literature, it is known that error rates are always different from $0 \%{ }^{2}$. The fact that the MLs used in the present study were trained as $80 \%$ training and $20 \%$ test set increases the prediction reliability of the study and makes it more advantageous when compared with discriminant analysis.

CT is preferred for providing advantage in the measurement of missing and damaged parts by making bone measurements very close to original and allowing for the reconstruction of each bone part, unlike conventional osteometry devices (calliper, odontometer, digital distance meter) ${ }^{16,23}$. As far as we know, studies that associate parameters taken from cranium and mandible on orthogonal plane with ML based sex prediction are very limited. Even if CT is used in current studies, the results can show differences because the orientation of the image is not converted to the orthogonal plane since especially angular measurements are parameters affected by orientation.

In their study they predicted sex from cranium by using CT, Gillet et al. ${ }^{24}$ used geometric morphometric model in their study and reported that they reached 0.90 Acc ratio for skull model. Zaafrane et al. ${ }^{25}$ reported that they estimated sex with an Acc ratio of 0.90 from parameters of cranium in CT images they analysed by using basic statistical methods. These differences in results can be explained with the fact that the evaluation of sexually dimorphic features depend on group specific standards and skeletal characteristics differ among different populations, as well as the methodological methods used and differences in statistical analyses.

It has been reported in literature that the possibility of removing the mandible intact is high ${ }^{26}$. The reason for this is the fact that the presence of a dense compact bone layer in the mandible makes it durable and therefore more likely to be found intact ${ }^{27}$. It is reported in literature that the measurements taken from the mandible are generally obtained from panoramic radiography images and that these images are affected by orientation ${ }^{28}$. According to the results of studies in which only the measurements taken from mandible are evaluated, an Acc ratio between 0.60 and 0.88 seems to be a reliable structure for sex prediction ${ }^{22,28-30}$. In this study, combining the parameters taken from the mandible with the cranium strengthened gender prediction. RML, CML, GCGA, CFL, PLL, PICA, CGC, PLIC, CGGIC, CGGIA parameters taken from the mandible were found to be statistically significant in sex identification.

Since the identity of individuals should be predicted quickly and accurately in events such as war, natural disasters and fire, which deeply affect the society, the CT technology and MLs used in the present study 
show that prediction time can be minimized and high accuracy can be obtained. Considering the high Acc ratio found as a result of LR algorithm, it is thought that the present study will strengthen and contribute to studies related with sex prediction.

\section{Materials And Methods}

\section{Image Set and Population}

The study was conducted at Karabuk University Training and Research Hospital, Department of Radiology after 2020/363 coded approval of Karabuk University Faculty of Medicine non-interventional clinical research ethics committee.

The image set in the study consisted of the CT images of 150 male and 150 female individuals whose ages ranged between 20 and 65 . Individuals with any surgical operation or pathology of the cranium skeleton were excluded from the study. Average age of the males was 54 ( $\min 20$, max 65), while average age of the females was ( $\min 21$, $\max 65$ ). No statistically significant difference was found between the average ages of males and females $(p=0.395)$.

\section{Multidetector Ct (Mdct) Protocol}

Radiological images used in the study were obtained from CT images with a section thickness of $5 \mathrm{~mm}$ taken in supine position by using a 16-row MDCT scanner (Aquilion 16; Toshiba Medical Systems, Otawara, Japan) in the department of radiology of a University Training and Research Hospital. Scanning protocol values were tube voltage: $120 \mathrm{kV}$, gantry rotation: $0,75 \mathrm{~s}$ and pitch: $1,0 \mathrm{~mm}$.

\section{Image Analysis}

The images obtained were transferred to Horos Medical Image Viewer (Version 3.0, USA) program, which is a personal workstation in Digital Imaging and Communications in Medicine (DICOM) format. Images in sagittal, transversal and coronal planes were obtained from the transferred images by using 3D Curved Multiplanar Reconstruction (MPR). The line passing through the nasion and inion points of the images in these three planes was determined and all images were brought to the orthogonal plane (Fig. 2A). Later, CT images brought to orthogonal plane were overlapped by increasing their section thicknesses (Fig. 2B).

Length, angle, area and curvature length measurements of the anatomic points of the overlapped images were performed. These parameters and their abbreviations are listed below in Tables 3, 4 and 5. Demonstration of all evaluated parameters is shown in Fig. 3. 
Table 3

Length parameters and abbreviations

\begin{tabular}{|ll|}
\hline Parameters & Abbreviations \\
\hline Ramus of the mandible lenght & $\mathrm{RML}$ \\
\hline Corpus of the mandible lenght & $\mathrm{CML}$ \\
\hline Head of mandible - mental foramen length & $\mathrm{HML}$ \\
\hline Coronoid process - obliqua line length & $\mathrm{COL}$ \\
\hline Nasion - nasal end point lenght & $\mathrm{NNL}$ \\
\hline
\end{tabular}

Table 4

Angle parameters and abbreviations

\begin{tabular}{|ll|}
\hline Parameters & Abbreviations \\
\hline Head of mandible- gonion - gnathion angle & HGGA \\
\hline Gonial angle & GA \\
\hline Gnathion - head of mandible- gonion angle & GHGA \\
\hline Coronoid process - obliqua line - infradental angle & COLI \\
\hline Coronoid process - mandibular notch - head of mandible angle & CMHA \\
\hline Nasion - vertex - inion angle & NVIA \\
\hline Zygomatic angle & ZA \\
\hline Nasion - inion - vertex angle & NIVA \\
\hline Nasal end point - nasion - zygomatic angle & NNZA \\
\hline Nasion - frontal tuber - inion angle & NFIA \\
\hline
\end{tabular}


Table 5

Curve lenght- area parameters and abbreviations

\begin{tabular}{|ll|}
\hline Parameters & Abbreviations \\
\hline Head of mandible - gonion - gnathion curvature length & HGGC \\
\hline Coronoid process - obliqua line - infradental curvature length & COIC \\
\hline Head of mandible - gonion - gnathion - mandibular notch curvature length & HGGMC \\
\hline Nasion - vertex - inion curvature length & NVIC \\
\hline Nasion - superciliary arch - vertex curvature length & NSVC \\
\hline Piriform aperture curvature length & PC \\
\hline Piriform aperture - Nasal end point - inion curvature length & PNIC \\
\hline Vertex - inion curvature length & VIC \\
\hline Nasal end point - inion curvature length & BIC \\
\hline Head of mandible - gonion - gnathion - mandibular notch area & HGGMA \\
\hline
\end{tabular}

\section{Machine Learning Algorithms}

In this study, scikit-learn model (Version 0.20.0) in Python programming language (Version 3.7.1) was used to make ML modelling ${ }^{31}$. ML modelling was performed by using i7, $8 \mathrm{GbHp}$-Folio 1040 model computer. Decision Tree (DT), Random Forest (RF), Logistic Regression (LR), Linear Discriminant Analysis (LDA), Quadratic Discriminant Analysis (QDA), Extra Tree Classifier (ETC) algorithms were used. Algorithms were trained to be $80 \%$ training and $20 \%$ test set.

\section{Performance Criteria}

Accuracy (Acc), Specificity (Spe), Sensitivity (Sen), F1 score (F1), and Matthews correlation coefficient (Mcc) values were included as performance criteria.

$$
\begin{gathered}
\text { Acc }=\frac{\mathrm{TP}}{\mathrm{TP}+\mathrm{FN}+\mathrm{FP}+\mathrm{TN}} \\
\text { Sen }=\frac{\mathrm{TP}}{\mathrm{TP}+\mathrm{FN}} \\
\text { Spe }=\frac{T N}{T N+F P}
\end{gathered}
$$




$$
\begin{gathered}
\text { Mcc }=\frac{\mathrm{TP} \times \mathrm{TN}-\mathrm{FP} \times \mathrm{FN}}{\sqrt{(\mathrm{TP}+\mathrm{FP}) \times(\mathrm{TP}+\mathrm{FN}) \times(\mathrm{TN}+\mathrm{FP}) \times(\mathrm{TN}+\mathrm{FN})}} \\
\mathrm{F} 1=2 \frac{\text { Specificity } \times \text { Sensitivity }}{\text { Specificity }+ \text { Sensitivity }}
\end{gathered}
$$

Equation 1. (TP: True positive, TN: True negative, FP: False positive, FN; False negative)

\section{Statistical Analysis}

Mean, standard deviation, minimum and maximum values were included in the descriptive statistics of each data according to gender groups. Normality test Anderson Darling test was applied to each parameter and it was checked whether the data were normally distributed. Two simple $T$ test was applied to parametric data and Mann-Whitney $U$ test was applied to nonparametric data and $p \leq 0.05$ value was considered as statistically significant. Minitab 17 package program was used in analyses.

Ethical considerations. This retrospective study was initiated with the 2020/363 decision of the Karabuk University Faculty of Medicine non-interventional clinical research ethics committee.

\section{Declarations}

\section{Ethical approval.}

The present study was approved by Karabuk University Faculty of Medicine Local Non-Interventional Clinical Trials Ethics Committee with the protocol number 2020/363. All procedures performed in studies involving human participants were in accordance with the ethical standards of the institutional and/or national research committee and with the 1964 Helsinki declaration and its later amendments or comparable ethical standards.

\section{Informed consent.}

This study is retrospective and based on images taken from the hospital archive system. Therefore, the requirement for informed consent for the study was waived by the Karabuk University Faculty of Medicine Local Non-Interventional Clinical Trials Ethics Committee.

Contributions: S.T., Y.S. Z.O., M.K.T., S.O., and D.S. conceived and designed this research work. M.K.T., S.O., and Y.S. image collection and data analysis. All authors reviewed the manuscript.

Acknowledgements: This research did not receive any specific grant from funding agencies in the public, commercial, or not-for-profit sectors.

Conflict of Interest: The authors declare that there is no conflict of interest. 
Footnote: This study was presented as an oral presentation at the $21^{\text {st }}$ National Anatomy Congress in Turkey

\section{References}

1 Nikita, E. \& Nikitas, P. On the use of machine learning algorithms in forensic anthropology. Legal Medicine47, 101771 (2020).

2 du Jardin, P., Ponsaillé, J., Alunni-Perret, V. \& Quatrehomme, G. A comparison between neural network and other metric methods to determine sex from the upper femur in a modern French population. Forensic science internationa/192, 127. e121-127. e126 (2009).

3 Darmawan, M., Yusuf, S. M., Kadir, M. A. \& Haron, H. Comparison on three classification techniques for sex estimation from the bone length of Asian children below 19 years old: an analysis using different group of ages. Forensic science internationa/247, 130. e131-130. e111 (2015).

4 Steyn, M. \& Işcan, M. Y. Metric sex determination from the pelvis in modern Greeks. Forensic science internationa/179, 86. e81-86. e86 (2008).

5 Plavcan, J. M. Sexual dimorphism in primate evolution. American Journal of Physical Anthropology: The Official Publication of the American Association of Physical Anthropologists116, 25-53 (2001).

6 Dawson, C., Ross, D. \& Mallett, X. in Forensic anthropology: 2000 to 2010 (CRC Press, 2011).

7 Mahfouz, M. et al. Patella sex determination by 3D statistical shape models and nonlinear classifiers. Forensic science internationa/173, 161-170 (2007).

8 Serkan, Ö., TURAN, M. \& Zülal, Ö. Estimation of Gender by Using Decision Tree, a Machine Learning Algorithm, With Patellar Measurements Obtained From MDCT Images. Medical Records3, 1-9 (2021).

9 Lin, C. et al. Sex determination from the mandibular ramus flexure of Koreans by discrimination function analysis using three-dimensional mandible models. Forensic science internationa/236, 191. e191-191. e196 (2014).

10 Kim, D.-I., Kim, Y.-S., Lee, U.-Y. \& Han, S.-H. Sex determination from calcaneus in Korean using discriminant analysis. Forensic science internationa/228, 177. e171-177. e177 (2013).

11 Akhlaghi, M. et al. Sex determination based on radiographic examination of metatarsal bones in Iranian population. International Journal of Medical Toxicology \& Forensic Medicine7, 203-208 (2017).

12 Turan, M. K., Oner, Z., Secgin, Y. \& Oner, S. A trial on artificial neural networks in predicting sex through bone length measurements on the first and fifth phalanges and metatarsals. Computers in biology and medicine115, 103490 (2019). 
13 Gapert, R., Black, S. \& Last, J. Sex determination from the occipital condyle: discriminant function analysis in an eighteenth and nineteenth century British sample. American Journal of Physical Anthropology: The Official Publication of the American Association of Physical Anthropologists138, 384394 (2009).

14 El Morsi, D. A. \& Al Hawary, A. A. Sex determination by the length of metacarpals and phalanges: X-ray study on Egyptian population. Journal of forensic and legal medicine20, 6-13 (2013).

15 Ozsoy, T., Oner, Z. \& Oner, S. An attempt to gender determine with phalanx length and the ratio of phalanxes to whole phalanx length in direct hand radiography. Medicine8, 692-697 (2019).

16 Oner, Z., Turan, M. K., Oner, S., Secgin, Y. \& Sahin, B. Sex estimation using sternum part lenghts by means of artificial neural networks. Forensic science internationa/301, 6-11 (2019).

17 Franklin, D., O'Higgins, P., Oxnard, C. E. \& Dadour, I. Determination of sex in South African blacks by discriminant function analysis of mandibular linear dimensions. Forensic science, medicine, and pathology2, 263-268 (2006).

18 Fawzy, I. A. \& Kamal, N. N. Stature and body weight estimation from various footprint measurements among Egyptian population. Journal of forensic sciences55, 884-888 (2010).

19 Bertsatos, A., Chovalopoulou, M.-E., Brůžek, J. \& Bejdová, Š. Advanced procedures for skull sex estimation using sexually dimorphic morphometric features. International Journal of Legal Medicine134, 1927-1937 (2020).

20 Krems, R. Bayesian machine learning for quantum molecular dynamics. Physical Chemistry Chemical Physics21, 13392-13410 (2019).

21 Franklin, D., Cardini, A., Flavel, A. \& Kuliukas, A. Estimation of sex from cranial measurements in a Western Australian population. Forensic Sci Int229, 158 e151-158, doi:10.1016/j.forsciint.2013.03.005 (2013).

22 Dayal, M. R., Spocter, M. A. \& Bidmos, M. A. An assessment of sex using the skull of black South Africans by discriminant function analysis. Homo59, 209-221 (2008).

23 Secgin, Y., Oner, Z., Turan, M. K. \& Oner, S. Gender prediction with parameters obtained from pelvis computed tomography images and decision tree algorithm. Medicine Science International Medical Journa/10, 356-361 (2021).

24 Gillet, C. et al. Sex estimation in the cranium and mandible: a multislice computed tomography (MSCT) study using anthropometric and geometric morphometry methods. International journal of legal medicine134, 823-832 (2020). 
25 Zaafrane, M. et al. Sex determination of a Tunisian population by CT scan analysis of the skull. International journal of legal medicine132, 853-862 (2018).

26 Franklin, D., O'Higgins, P., Oxnard, C. E. \& Dadour, I. Discriminant function sexing of the mandible of indigenous South Africans. Forensic Science Internationa/179, 84. e81-84. e85 (2008).

27 Saini, V. et al. Mandibular ramus: An indicator for sex in fragmentary mandible. Journal of forensic sciences56, S13-S16 (2011).

28 Indira, A. P., Markande, A. \& David, M. P. Mandibular ramus: An indicator for sex determination-A digital radiographic study. Journal of forensic dental sciences4, 58 (2012).

29 Steyn, M. \& İşcan, M. Y. Sexual dimorphism in the crania and mandibles of South African whites. Forensic science internationa/98, 9-16 (1998).

30 Marinescu, M., Panaitescu, V. \& Rosu, M. Sex determination in Romanian mandible using discriminant function analysis: Comparative results of a time-efficient method. Rom J Leg Med21, 305-308 (2013).

31 Pedregosa, F. et al. Scikit-learn: Machine learning in Python. the Journal of machine Learning research12, 2825-2830 (2011).

\section{Figures}




\section{Logistic Regression (ACC: \%90)}

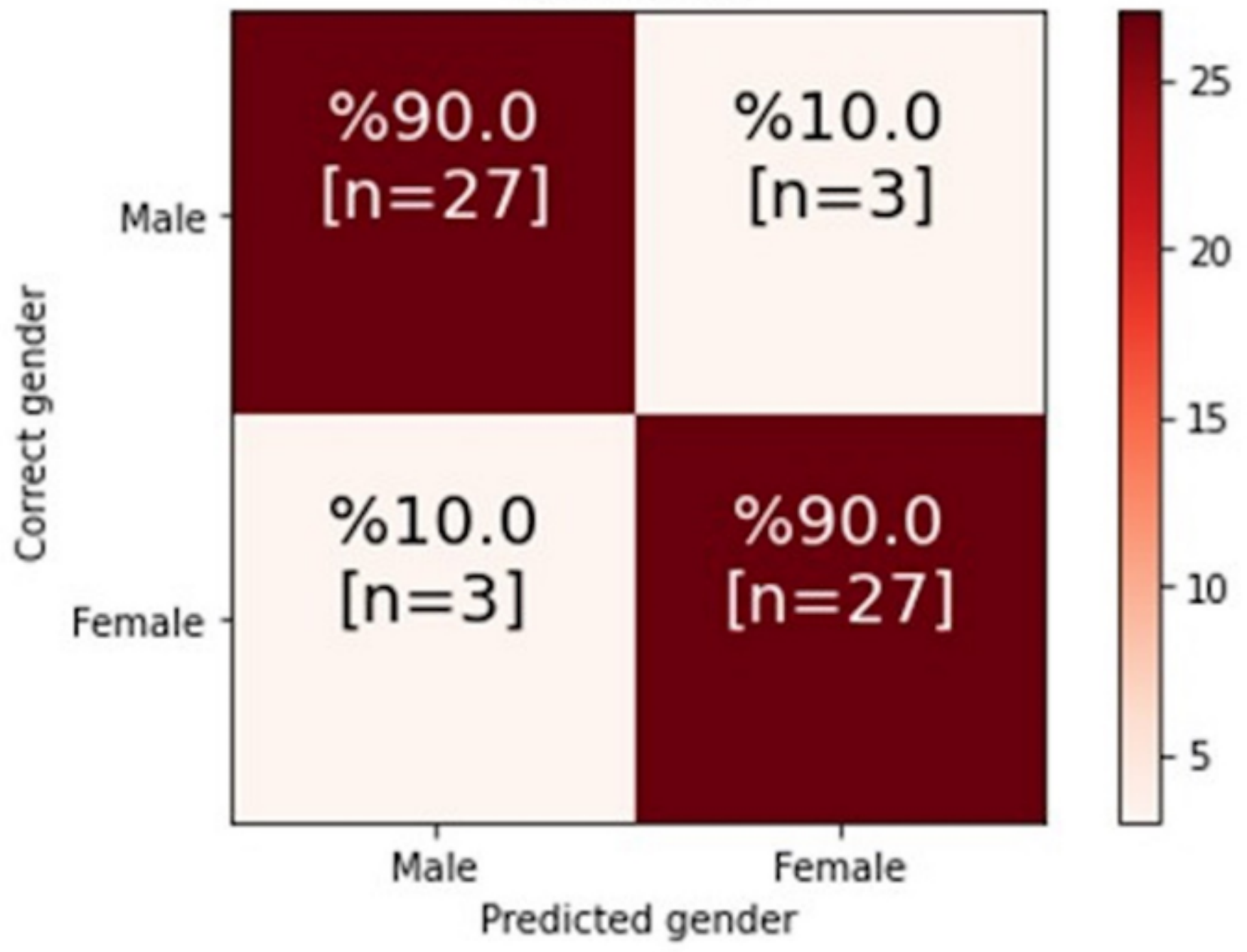

Figure 1

LR Confusion Matrix

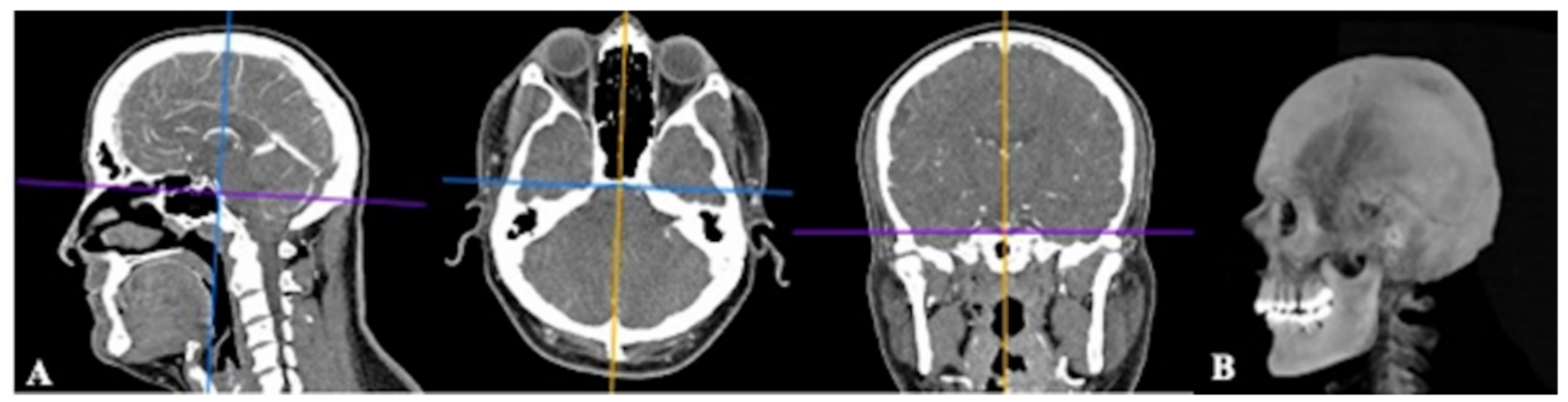

Figure 2

A. Sagittal, transversal and coronal images brought to orthogonal plane, B. Overlapped image 


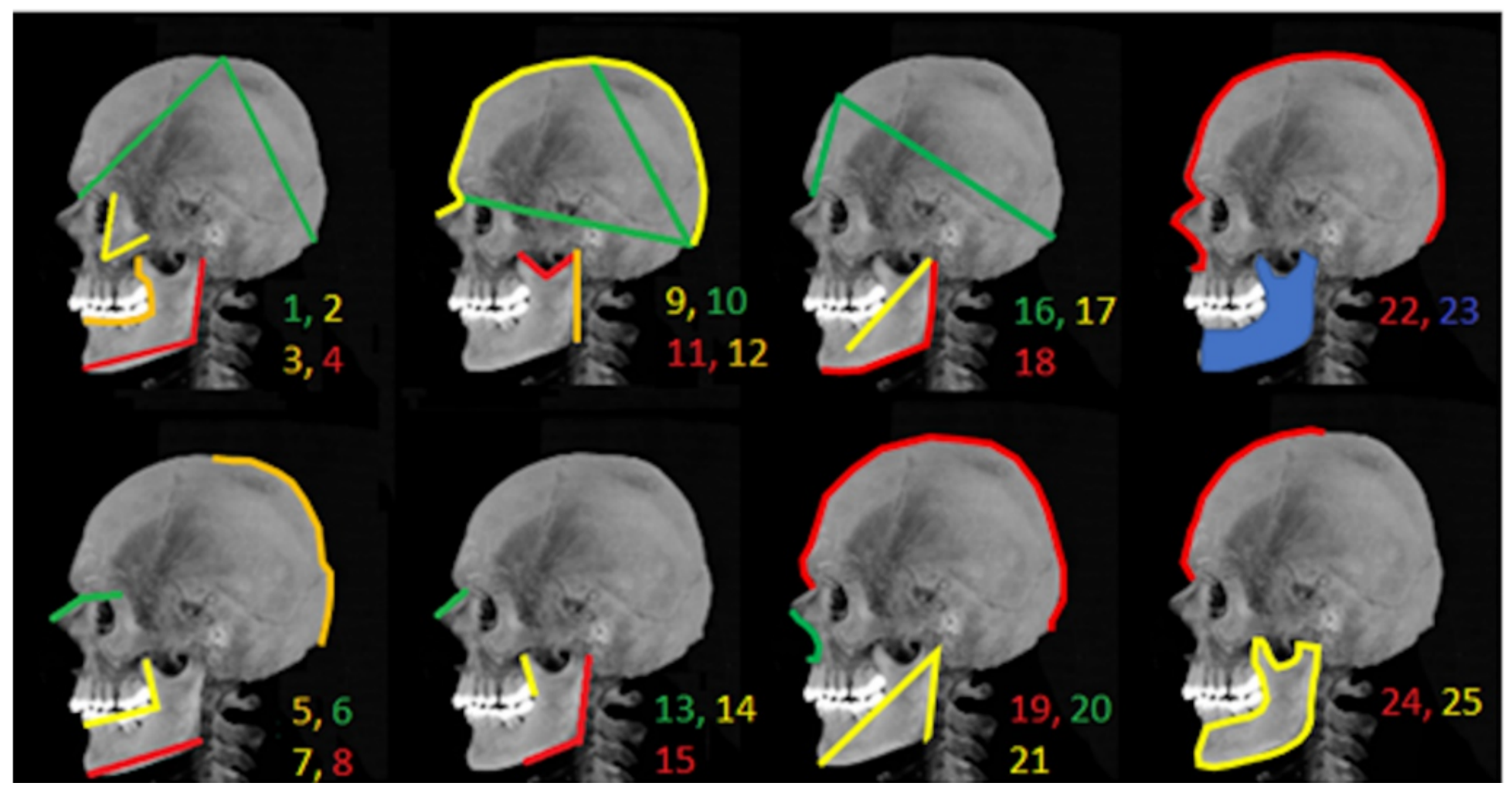

\section{Figure 3}

Demonstration of parameters (1: NVIA, 2: ZA, 3: COIC, 4: HGGA, 5: VIC, 6: NNZA, 7: COLI, 8: CML, 9: NIC, 10: NIVA, 11: CMHA, 12: RML, 13: NNL, 14: COL, 15: GA, 16: NFIA, 17: HML, 18: HGGC, 19: NVIC, 20: PC, 21: GCGA, 22: PNIC, 23: HGGMA, 24: NSVC, 25: HGGMC) 